\title{
The Impact of Social Media on Rural Educated Women in the Context of Epidemic
}

\author{
Sushma Kumari \\ Indra Gandhi National Open University, New Delhi, India \\ sushmakumari94193@hotmail.com
}

\begin{abstract}
In today's society, the use of social media has become a part and parcel of life. Social media is typically used for social interaction and access to news and information and decision making. It is a valuable communication tool to share, create and spread information locally and internationally. This study was conducted in the Khour block of Jammu district by ascertaining the impact of social Media on Rural Educated women. The study has found that the usage of social media has some constructive and unconstructive effects on society Social media positively affects gender inequality by promoting knowledge and ideas and marginally promotes social values and norms. It was also found that social media motivates the women to take active involvement in politics. Moreover, the social media unconstructively affects certain things like adoption of foreign culture and civilization, wastage of precious time. The study has also revealed that usage of Social Media has a tremendous effect on social life style of Rural Educated Women. Keywords: Social Media, Life Style, Rural Educated Women, Social Norms and Ethics.
\end{abstract}

Keywords: Social Media, Life Style, Rural Educated Women, Social Norms and Ethics

\section{Introduction}

Social media is a collective term for applications and websites that focus on communication, community based input, interaction, collaboration and content sharing. Social media is becoming part of our society, changing social norms and culture (Al-Sharqi \& Kutbi, 2015). It is the social media through which people can stay in touch with friends, family and various communities. Social media has enormous traction globally. Mobile applications make these platforms simple and easy accessible. Social media has a significant impact on life style of women. Social media effects the women's life, sometimes impacts are in the favors of women's social life and sometimes these impacts are negative to its users (Sushila, 2013)

Social media is also used for crowd sourcing. That's the practice of using social networking to gather knowledge, goods or services. Business ventures use crowd sourcing to get ideas from customers, employees and the general public for improving products or developing future products or services. Now - a -day people used to share information via social network. Information and content sharing is now a social desire (Wolf et al, 2016)

More than half of the people around the world now use some form of social media. For businesses, this mean it is possible to reach nearly any type of consumer on these platforms. There are a number of social websites and apps available, all with diverse features and niches. So each business must create its own social media mix aimed at its target customers. According to Pew Research Center, these are the percentages of US adults that use social media sites online or on mobile:

- YouTube: $73 \%$

- Facebook: $68 \%$

- Instagram: $35 \%$

- Pinterest: $29 \%$

- Snapchat: $27 \%$

- Linkedln: $25 \%$
- Twitter: $24 \%$

\subsection{Benefits of Social media}

Social media provides several benefits, including the following:

- User Visibility: Social platforms let people easily communicate and exchange ideas or contents. People are connected to each other far beyond the geographical boundaries. the growing trend in social media has increased knowledge, sharing and transfer of information has become easier, women's can now easily share information and post both motivational thoughts on social media. The usage of social media for women has become a way of life and personal activities are made public (Satpathi, 2011)

- Audience Building: One of the great benefits of social media is that it helps the entrepreneurs and artists to build an audience base for their work. In some cases, social media has eliminated the need for a distributor, because everyone can upload their and transact business online. For instance a singer can post a song on Facebook, gets instant visibility among their network of friends, who in turn share it on their networks.

- Direct connection with audiences: Social media is one of the few marketing strategies that allow you to connect directly with your audience. You know who is interested in your business because they choose to follow your social media account. This social media helps your business in numerous ways like you get to know your customer better, you provide them better customer services, you get valuable insight about your customer and the like.

- Build your brand: One advantage of social media marketing is the ability to build your brand. When you connect with interested leads, you expose them to your brand. The ability to post organic content for free allows you to build brand recognition repeatedly with your audience. 
- Drive traffic to your website: Social media is a great catalyst for driving traffic to your businesses website. A number of social media platforms allow you to post content with a link to your website. When you create compelling content, you can entice your audience click on the link. This directs them to your site, where they can learn more about your business.

\subsection{Disadvantages of Social Media}

With any marketing strategy, there are always disadvantages. The disadvantages don't mean that the approach is not effective, but rather, present potential hurdles you may have to jump through during your compaign. The disadvantages of social media are highlighted in the following points:

- Lack of emotional connection

- Decrease face to face communication skills

- Conveys Inauthentic expression of feelings reduces family closeness

- Diminishes understanding and thoughtfulness

- You can receive negative feedback.

\section{Review of Literature}

(Mingle, J., \& Adams, M., 2015) have argued in their study that the usage of Social Media negatively causes bad hand writing and spelling, delay in class and assignment submission, addiction and others. They further asserted that Social media changes educational settings and learners behavior.

(Davis, 2012), in their study the authrs have described Social Media Technology as "web - based and mobile applications that allow individuals and organizations to create, engage and share new user generated or existing content in digital environments through multi way communication". Through this platform, individuals and organizations create profiles share and exchange information on various activities and interests.

(Boyd, D. M. and Elisson, N. B., 2007) Social Media sites are web - based services that allow individuals to construct a public or semi public profile within a bounded system, articulate a list of other users with whom they share a connection and view and transverse their list of connections and those made by others within the system". The information shared via this platform includes news, debates, feelings, opinions and the like.

(Banquil et.al, 2009) In their study, they have found that a continuing drop of grades among students who use social networking sites. His study was backed by (Kirschner, P. A. \& Karpinski, A. C., 2010) who found a significant negative relationship between Facebook use and Academic performance. They concluded that students who use Facebook spend fewer hours per week studying on an average than Facebook non users and this result in lower mean grade point averages.

(Kumari, 2020) In the article the researcher has focused on how social media is used to empower women and encourage the women entrepreneur from rural and urban parts of India. The study also discussed how social media became powerful platform for the discussion of women rights and encouraging government and policy makers to step up commitments and formulate policies for gender equality. This study has concluded that social media platform has raised the voice of oppressed women and has compelled world to think about the gender equality and women empowerment.

(Helbergert, H \& Loken, E., 2011) highlighted that the use of Social Media has led to series of female violence through arranged meetings with social media male friends. Social Media encompasses internet website, service and practices that enhanced shared of information among people. One of the internet website like Facebook which is also the most used social media platform among women's have significant effect on their educational performance.

\section{Research Methodology}

This study involves both primary and secondary data sources. The primary data was collected through a questionnaire, while the secondary data was also built using literature study and was collected from books, journals, reports, articles and so on and so forth. This study focused on the Impact of Social Media on Rural Educated women: A study of Khour block of Jammu district. The study involved random sampling method in the rural areas of Khour block of Jammu district. The sample size of 60 rural women falling within the age group of 18 to 40 with minimum qualification of $12^{\text {th }}$ were selected on simple random sampling basis and the required data was collected from them through a well drafted questionnaire by keeping the objectives of the study in mind.

\section{Objectives of Study}

- To assess the impact of Social Media on the Social Life Style of Rural Educated women

- To evaluate the positive and negative impact of social media on the life style of Rural Educated women

\section{Discussion and Analysis}

The results of table 1 and 2 are presented in the following manner: Strongly agree $(\mathrm{SA})+$ Agree $(\mathrm{A})=$ Agree $(\mathrm{A})$. Disagree $(D)+$ Strongly Disagree $(\mathrm{SD})=$ Disagree $(\mathrm{D})$. Not Sure stands alone. For analysis purpose the study focused on A and D. however, Not Sure rural women results were not considered in the analysis because their opinion cannot be matched to either Agree or Disagree. 
Social media has also a tremendous role in motivating the women class to take part in politics by contesting elections. As far as the findings of this study is concerned about $58.33 \%$ of the respondents believing that Social media encourage and motivate them through its contents and activities to join or develop interest in politics. It is also revealed by the study that $26.67 \%$ participants do not get any motivation from Social Media to involve in politics. In nutshell, the findings depict that the use of social media content and views about politics bring good inspiration for educated rural women to join and take part in politics.

\section{Research Findings}

The following is the list of research findings of the study:

- The social life style of educated rural women is effected by social media and influence their views about life in general

- It was also found that usage of social media marginally promotes social values and norms.

- The educated rural women have also argued that usage of social media have disvalued their consideration and value 'on marriage as an institution in the society.

- One of the negative impact of the usage of social media by rural educated women promotes adoption of foreign culture and civilization.

- The study has also found that the excessive use of social media by the rural educated women result in time more consuming, which negatively affect the society and economy.

- The findings also proved that social media promote knowledge and ideas to diminish the problem of gender inequality and balance the society.

\section{Conclusion}

Social media is important because it allows you to reach, nurture and engage with your target audience - no matter their location. When a business can use social media to connect with its audience, it can use social media to generate brand awareness, which leads sales and generate revenue. This study was carried out to discover the diverse impacts of social media usage on social life style of educated rural women and was also held to discover the positive and negative aspects of using social media. The study has revealed that the use of social media affect the social life of rural educated women and marginally promotes social values and norms. Moreover, the use of social media affects positively and negatively the rural educated women like social media is able to reduce the gap of gender inequality, it promotes adoption of foreign culture and civilization and one's own culture fades away.

\section{References}

[1] Mingle, J., \& Adams, M. (2015). Social media network participation and academic performance in senior high schools in Ghana. Library Philosophy and Practice.

[2] Al - Sharqi, \& Kutbi, L. H. (2015). Perceptions of Social Students Media Impact on Students Social Behaviour: A comparsion between Arts and Science.
International Journal of Education and Social Science, 2 (4), 122 - 131.

[3] Banquil et. al. (2009). Social Networking sites effect one's academic performance adversely. Retrived August 12, 2014 from http: //www.ust. edu. ph.

[4] Boyd, D. M. and Elisson, N. B. (2007). Social network sites: Definition, history, and Scholarship. Journal of Computer - Mediated Communication., 1 (13).

[5] Davis, C. H. - A. - A. (2012). Social Media in Higher Education: A Literature Review and Research Directions. Arizona: The Center for the Study of Higher Education at the University of Arizona and Claremont $\mathrm{G}$.

[6] Helbergert, H \& Loken, E. (2011). The Effect of Twitteron College Student Engagement and Grades. Journal of Computer Assisted Learning, 27 (2).

[7] Joshua Chukwuere \& P. C. Chukwuere. (2017). The Impact of Social Media on Social Lifestyle: A Case Study of University female students. Gender and Behaviour, 9928 - 9940.

[8] Kirschner, P. A. \& Karpinski, A. C. (2010). Facebook and academic performance. Computers in Human Behaviour, 1237 - 1245.

[9] Kumari, M. (2020). Social Media and Women Empowerment. International Journal of Scentific and Technology Research, 9 (3), 626 - 629.

[10] Satpathi. (2011). The Impact of the Electronic Media on Modern Indian Voter. A Study of the post Liberalization Era. GMJ, 2 (6).

[11] Sushila, A. (2013). ICT Education for Rural Women and Girls: A Case of Computer Education. IJAR, 3 (3).

[12] Williams, L. M. (2012). Facebook ruined my marriage: Digital IntimacyInterference on Social Networking sites (Doctoral Dessertation, Syracuse University).

[13] Wolf et al. (2016). Nurses use of the Internet and Social Media: Does age, year of experience and education level make a difference. Journal of Nursing Education and Practice, 6 (2), 68 - 75. 